\title{
Introduction and Overview on Myopia: A Clinical Perspective
}

\author{
Chee Wai Wong, Noel Brennan, and Marcus Ang
}

\section{Key Points}

- Myopia is a significant global public health and socioeconomic problem.

- Pathologic myopia has become a major cause of blindness or visual impairment in both Asian and Western populations.

- Myopia may be a highly heritable trait, with environmental influences such as outdoor activity playing important roles in its development and progression.

- Control of myopia in children is important, and various strategies including pharmacologic and lens-related interventions have proven efficacy.

- Imaging is important to detect complications of pathologic myopia, and both medical and surgical interventions may be useful for their management.

C. W. Wong · M. Ang $(\bowtie)$

Singapore National Eye Centre, Singapore Eye Research Institute, Singapore, Singapore

Duke-NUS Medical School, Singapore, Singapore

e-mail: marcus.ang@ snec.com.sg

N. Brennan

R\&D, Johnson \& Johnson Vision Care, Inc, Jacksonville, FL, USA 


\subsection{Global Epidemiology}

Myopia has become a significant global public health and socioeconomic problem [1-4]. East Asia, and other parts of the world to a lesser extent, has been faced with an increasing prevalence of myopia [5, 6]. The prevalence of myopia and high myopia (HM) (the definition of myopia and HM is spherical equivalence (SE) of -0.50 diopters (D) or less and SE -5.00 D or $-6.00 \mathrm{D}$, respectively) in young adults in urban areas of East Asian countries has risen to $80-90 \%$ and around $20 \%$, respectively [7, 8]. According to a summary of 145 studies regarding the global prevalence of myopia and HM, there are approximately 1950 million with myopia (28.3\% of the global population) and 277 million with HM (4.0\% of the global population), and these numbers are predicted to increase to 4758 million (49.8\% of the global population) for myopia, and 938 million (9.8\% of the global population) for HM by 2050 [9].

The prevalence of childhood myopia is substantially higher in urban East Asian countries (49.7-62.0\% among 12-year-old children) [7, 10] compared with other countries (6.0-20.0\% among 12-year-old children) [9]. Similarly, in teenagers and young adults, the prevalence of myopia is higher in East Asian countries (65.596.5\%) [8] compared with other countries (12.8-35.0\%) [9]. However, the geographic difference of myopia prevalence in older populations is less than that in younger populations. The prevalence rates of myopia in adults in urban East Asian countries are only slightly higher than in Western countries.

The prevalence of myopia has remained consistently high among Chinese children in urban settings, but the evidence does not support the idea that it is caused by purely genetic difference [10]. The association of an urbanized setting with high myopia rates is likely to be influenced by possible modifiable risk factors such as near work and outdoor time.

Despite the relatively low prevalence in the general population, pathologic myopia (PM) is a major cause of blindness or visual impairment in both Asian and Western populations. One study has shown that the prevalence of PM was $28.7 \%$ among high myopes and $65 \%$ of those with HM and were over 70 years old had PM [11]. Based on the global prediction of HM on 2050, PM may increase to over 200 million in future [9]. Treatment strategies against PM have not been effective [12].

Generational differences in prevalence are seen with the highest rates in young adults (myopia 65.5-96.5\% and HM 6.8-21.6\%) and the lowest rates in older adults (myopia 25.0-40.0\% and HM 2.4-8.2\%). The disease progression pattern of HM and subsequent development of PM may be different between young adults and older adults due to generational differences, or changes in the lifestyle factors such as the education system, near work, and outdoor time exposure in rapidly developing urban Asian countries.

\subsection{Pathogenesis of Myopia}

Ocular Biometric Changes in Human Myopia The axial length of the eye or, more precisely, the vitreous chamber depth is the primary individual biometric contributor to refractive error in children, young adults, and the elderly [13-15], with 
the vitreous chamber depth accounting for over $50 \%$ of the observed variation in spherical equivalent refractive error (SER), followed by the cornea $(\sim 15 \%)$ and crystalline lens $(\sim 1 \%)$ [15]. However, the dimensions, curvature, and refractive index of each individual ocular structure contribute to the final refractive state. The choroid is typically thinner in myopic compared to non-myopic eyes (most pronounced at the fovea $[16,17])$ and thins with increasing myopia and axial length in both adults [18-25] and children [26-28]. Significant choroidal thinning is also observed in eyes with posterior staphyloma [29], and has been associated with the presence of lacquer cracks [30], choroidal neovascularization [31], and reduced visual acuity [32]. The choroid also appears to be a biomarker of ocular processes regulating eye growth given that the central macular choroid thins during the initial development and progression of myopia [33-35] and thickens in response to imposed peripheral myopic retinal image defocus [36, 37], topical anti-muscarinic agents [38, 39], and increased light exposure [40]; clinical interventions associated with a slowing of eye growth in children.

Visual Environment, Emmetropization, and Myopia Much of the knowledge on vision-dependent changes in ocular growth has emanated from animal experiments in which either the quality of image formed on the retina is degraded (known as form deprivation [FD]), or the focal point of the image is altered with respect to the retinal plane (known as lens defocus). Both FD and lens defocus result in abnormal eye growth and development of refractive errors.

Monochromatic Higher-Order Aberrations as a Myopigenic Stimulus Myopia may develop due to the eye's emmetropization response to inherent ocular aberrations that degrade retinal image quality and trigger axial elongation [41]. Evidence concerning the relationship between higher order abberation (HOAs) during distance viewing and refractive error from cross-sectional studies is conflicting [41, 42]. However, during or following near-work tasks, adult myopic eyes tend to display a transient increase in corneal and total ocular HOAs, suggesting a potential role for near-work-induced retinal image degradation in myopia development [43, 44]. Longitudinal studies of myopic children also indicate that eyes with greater positive spherical aberration demonstrate slower eye growth $[45,46]$.

Accommodation Given the association between near work and the development and progression of childhood myopia [47], numerous studies have compared various characteristics of accommodation between refractive error groups. Typically, this involves the accuracy of the accommodation response, since lag of accommodation (hyperopic retinal defocus) may stimulate axial elongation as observed in some animal models. The slowing of myopia progression during childhood with progressive addition or bifocal lenses, designed to improve accommodation accuracy and minimize lag of accommodation, adds some weight to the role of accommodation in myopia development and progression [48, 49]. However, the exact underlying mechanism of myopia control with such lenses may be related to imposed peripheral retinal defocus or a reduction in the near vergence demand [50]. Certainly, elevations in measured lag observed in myopes arise after rather than before onset [51]. 


\subsection{Key Environmental Factors on Myopia}

Near work and education: Many studies have established a strong link between myopia and education [52-57]. Moreover, Mountjoy et al. have shown that exposure to longer duration of education was a causal risk factor for myopia [53]. The exact mechanism linking increased education with myopia is unclear. Although it is possible that optical $[43,58]$ or biomechanical $[59,60]$ ocular changes associated with near work could potentially promote myopic eye growth in those with higher levels of education (and hence near-work demands), population studies examining the link between near-work activities and myopia have been conflicting, with some studies suggesting an association between near work and myopia [47, 61], and others indicating no significant effects [62]. The relatively inconsistent findings linking near work with myopia development suggests a potential role for other factors in the association between education and myopia.

Outdoor Activity A number of recent studies report that the time children spend engaged in outdoor activities is negatively associated with their risk of myopia [62-68]. Both cross-sectional and longitudinal studies indicate that greater time spent outdoors is associated with a significantly lower myopia prevalence and reduced risk of myopia onset in childhood. Although some studies report significant associations between myopia progression and outdoor activity $[66,68]$, this is not a consistent finding across all longitudinal studies [69]. A recent meta-analysis of studies examining the relationship between outdoor time and myopia indicated that there was a $2 \%$ reduction in the odds of having myopia for each additional hour per week spent outdoors [70].

Duration of Outdoor Activity and Myopia In a large longitudinal study, Jones and colleagues [62] reported that children who engaged in outdoor activities for $14 \mathrm{~h}$ per week or more exhibited the lowest odds of developing myopia. A number of recent randomized controlled trials have reported that interventions that increase children's outdoor time (by 40-80 min a day) significantly reduce the onset of myopia in childhood [71-73]. In the "Role of outdoor activity in myopia study" [74], children who were habitually exposed to low ambient light levels (on average less than $60 \mathrm{~min}$ exposure to outdoor light per day) had significantly faster axial eye growth compared to children habitually exposed to moderate and high light. These findings from human studies suggest that children who are exposed to less than $60 \mathrm{~min}$ a day of bright outdoor light are at an increased risk of more rapid eye growth and myopia development, and that approximately $2 \mathrm{~h}$ or more of outdoor exposure each day is required to provide protection against myopia development in the human eye.

\subsection{Genetics of Myopia}

Myopia is highly heritable; genes explain up to $80 \%$ of the variance in refractive error in twin studies. For the last decade, genome-wide association study (GWAS) approaches have revealed that myopia is a complex trait, with many genetic variants 
of small effect influencing retinal signaling, eye growth, and the normal process of emmetropization. Particularly notable are genes encoding extracellular matrixrelated proteins (COL1A1, COL2A1 [75, 76], and MMP1, MMP2, MMP3, MMP9, MMP10 [77, 78]). For candidates such as PAX6 and TGFB1, the results were replicated in multiple independent extreme/high myopia studies and validated in a large GWAS meta-analysis in 2018, respectively [79, 80]. However, the genetic architecture and its molecular mechanisms are still to be clarified, and while genetic risk score prediction models are improving, this knowledge must be expanded to have impact on clinical practice.

Gene-environment ( $\mathrm{GxE}$ ) interaction analysis has focused primarily on education. An early study in North American samples examined GxE for myopia and the matrix metalloproteinases genes (MMP1-MMP10): a subset of single nucleotide polymorphism (SNPs) was only associated with refraction in the lower education level [78, 81]. A subsequent study in five Singapore cohorts found variants in DNAH9, GJD2, and ZMAT4, which had a larger effect on myopia in a high education subset [82]. Subsequent efforts to examine GxE considered the aggregate effects of many SNPs together. A study in Europeans found that a genetic risk score comprising 26 genetic variants was most strongly associated with myopia in individuals with a university level education [83]. A study examining GxE in children considered near work and time outdoors in association with 39 SNPs and found weak evidence for an interaction with near work [83, 84]. Finally, a Consortium for Refractive Error and Myopia (CREAM) study was able to identify additional myopia risk loci by allowing for a $\mathrm{GxE}$ approach [85].

Mendelian randomization (MR) offers a better assessment of causality than that available from observational studies [86, 87]. Two MR studies found a causal effect of education on the development of myopia $[53,80]$. Both found a larger effect through MR than that estimated from observational studies suggesting that confounding in observational studies may have been obscuring the true relationship [55, 79]. As expected, there was little evidence of myopia affecting education $(-0.008$ years/ diopter, $P=0.6$ ). Another study focused on the causality of low vitamin D on myopia found only a small estimated effect on refractive error [88] suggesting that previous observational findings were likely confounded by the effects of time spent outdoors.

Due to the high polygenicity of myopia and low explained phenotypic variance by genetic factors $(7.8 \%)$, clinical applications derived from genetic analyses of myopia are currently limited. Risk predictions for myopia in children are based on family history, education level of the parents, the amount of outdoor exposure, and the easily measurable refractive error and axial length. Currently, we are able to make a distinction between high myopes and high hyperopes based on the polygenic risk scores derived from CREAM studies: persons in the highest decile for the polygenic risk score had a 40-fold greater risk of myopia relative to those in the lowest decile. A prediction model, including age, sex, and polygenic risk score, achieved an area under curve (AUC) of 0.77 (95\% CI $=0.75-0.79)$ for myopia versus hyperopia in adults (Rotterdam Study I-III) [80]. To date, one study has assessed both environmental and genetic factors together and showed that modeling both genes and environment improved prediction accuracy [89]. 


\subsection{Prevention of the Onset of Myopia}

The vast majority of literature suggests that most cases of myopia develop during the school-going age in children. After the age of 6 years, the prevalence of myopia starts to rise [90-94]. The highest annual incidence of myopia is reported among school children from urban mainland China [92] and Taiwan [95], ranging from $20 \%$ to $30 \%$ through ages $7-14$ years, with earlier onset of myopia also being identified [94]. A study in Japan showed that while the prevalence of myopia has been increasing from 1984 to 1996, the prevalence among children aged 6 or younger has remained unchanged. This suggests that the majority of increased myopia onset is secondary to increased educational intensity [94].

Rates of progression increase dramatically with the year of onset and this has been suggested by spherical equivalent refraction and axial length [96]. Myopic refractions tend to stabilize in late adolescent but can remain progressive until adulthood. The mean age at myopia stabilization is 15.6 years but this can vary among children of different ethnicities [97].

Several factors have been found to be associated with the development of incident myopia in school. Asian ethnicity [93, 98], parental history of myopia [62, 99], reduced time outdoors [62], and level of near-work activity [47, 100] are risk factors for incident myopia, although the evidence can be seen as controversial in some instances.

Evidence of time spent outdoors as a risk factor for myopia progression was first presented in a 3-year follow-up study of myopia in school children, showing that those who spent more time outdoors were less likely to progress [64]. Consistent results were reported in various studies, such as the Sydney Myopia Study, Orinda Study, as well as the Singapore Cohort Study of Risk Factors for Myopia [63, 65, 101]. This led to the commencement of several clinical trials which confirmed the protective effect and indicated a dose-dependent effect, among them, the randomized clinical trial in Guangzhou which reported that an additional 40 min of outdoor activity can reduce the incidence of myopia by $23 \%$ [63]. Additionally, the trial in Taiwan suggested that an extra 80 min may further reduce incidence by $50 \%$ [72, 73].

Near-work activity as a risk factor for myopia has not been entirely consistent. A meta-analysis reported a modest, but statistically significant, association between time spent performing near work and myopia (odds ratio, 1.14) [47]. Core techniques to implementing interventions of near-work activities include effective measures of near-work-related parameters, real-time data analyses, and alert systems. Wearable devices that possess these techniques have emerged in the last decade.

It has been estimated that without any effective controls or interventions the proportion of myopes in the population will reach up to $50 \%$ and $10 \%$ for high myopes by 2050 [9]. Approaches that have produced a reduction of at least $50 \%$ in incidence, such as time outdoors, lead to delayed onset and have the potential to make a significant difference on the impending myopia epidemic.

Another critical issue is the need to balance educational achievement and interventions to prevent myopia progression in East Asia. This balance can be seen in Australia [102], with not only some of the highest educational ranks in the world but 
also high levels of outdoor activity and light intensity. Preventing the onset of myopia is certainly challenging in the East Asian population and requires a collaborative effort among clinics, schools, parents, and the entire society.

\subsection{Understanding Pathologic Myopia}

Pathologic myopia (PM) is a major cause of blindness in the world, especially in East Asian countries [103-107]. The cause of blindness in patients with PM includes myopic maculopathy with or without posterior staphyloma, myopic macular retinoschisis, and glaucoma or glaucoma-like optic neuropathy. The term "pathologic myopia" describes the situation of pathologic consequences of a myopic axial elongation. According to a recent consensus article by Ohno-Matsui et al. [108], pathologic myopia was defined by a myopic chorioretinal atrophy equal to or more serious than diffuse atrophy (by Meta-analysis for pathologic myopia (META-PM) study group classification [109]) and/or the presence of posterior staphylomas.

A posterior staphyloma is an outpouching of a circumscribed area of the posterior fundus, where the radius of curvature is less than the curvature radius of the surrounding eye wall [110], and can be associated with, or lead to, vision-threatening complications such as myopic maculopathy [109, 111-114] and myopic optic neuropathy/glaucoma [115, 116]. Based upon and modifying Curtin's [117] classical categorization of posterior staphylomas, with types I-V as primary staphylomas and types VI-X as compound staphylomas, Ohno-Matsui [118] used 3D-magnetic resonance imaging (3D-MRI) and wide-field fundus imaging to re-classify staphylomas into six types: wide macular, narrow macular, peripapillary, nasal, inferior, and others.

In the META-PM classification [109], myopic maculopathy lesions have been categorized into five categories from "no myopic retinal lesions" (category 0), "tessellated fundus only" (category 1), "diffuse chorioretinal atrophy" (category 2), "patchy chorioretinal atrophy" (category 3), to "macular atrophy" (category 4). These categories were defined based on long-term clinical observations that showed the progression patterns and associated factors of the development of myopic choroidal neovascularization $(\mathrm{CNV})$ for each stage. Three additional features were added to these categories and were included as "plus signs": (1) lacquer cracks, (2) fuch spot and (3) myopic CNV.

Myopic CNV is a major sight-threatening complication of pathologic myopia. It is the most common cause of CNV in individuals younger than 50 years, and it is the second most common cause of CNV overall [119, 120]. Anti-vascular endothelial growth factor (anti-VEGF) therapy is the first-line treatment for myopic CNV, as shown by the RADIANCE study [121] and the MYRROR study [122].

Panozzo and Mercanti proposed the term "myopic traction maculopathy (MTM)" to encompass various findings characterized by a traction as visualized by optical coherence tomography (OCT) in highly myopic eyes [123]. A dome-shaped macula (DSM) is an inward protrusion of the macula as visualized by OCT [124-126]. Imamura, Spaide, and coworkers reported that a DSM was associated with, and 
caused by, a local thickening of the subfoveal sclera [127]. It was postulated that the local thickening of the subfoveal sclera was an adaptive or compensatory response to the defocus of the image on the fovea in highly myopic eyes.

\subsection{Imaging in Myopia}

Imaging the myopic eye can be challenging due to various structural changes (abnormal eye elongation, scleral and corneal curvature irregularities, cataracts leading to poor clarity; or retinal thinning causing abnormal projections of the final image [128, 129]).

Optic disc imaging can also be used to predict the development of glaucoma, where visualization of myopic tilting of the optic disc with peripapillary atrophy (PPA) and pitting of the optic disc [130] is a possible predisposing factor [131, 132]. Serial imaging investigative measures can therefore be utilized for monitoring the development of open-angle, normal-tension glaucoma [133]. Features such as optic disc tilt, PPA, and abnormally large or small optic discs are the earliest known structural alterations that potentially predict the development of pathological myopia and can be observed even in young highly myopic adults. Unfortunately, these features (some also with associations to glaucoma) also interfere with the visualization of optic disc margins $[134,135]$ and are also not easy to discern in highly myopic eyes [136]. There is also added difficulty in eyes with myopic maculopathy, where visual field defects result in further interference [137]. As such, the answer to these challenges may lie in imaging deep optic nerve head structures (such as parapapillary sclera, scleral wall, and lamina cribosa) [138] in highly myopic eyes for more precise diagnoses of glaucoma.

The ability to view distinct retinal layers with OCT has enhanced visualization of myopic traction maculopathy (MTM). Examples of features that can be seen include inner or outer retinal schisis, foveal detachment, lamellar or full-thickness macular hole, and/or macular detachment [139, 140]. Non-stereoscopic fundus photographs are inadequate for detailed studies of posterior staphylomas as the change in contour at the staphyloma edge is not always discernible. The OCT overcomes this limitation because of its excellent depth resolution [141, 142].

The OCT itself has its shortcomings; the sclera cannot be visualized using the OCT. These limitations also extend to the use of OCT angiography (OCTA). There is currently no standard protocol for segmentation; the outcome parameters for OCTA have not been clearly defined either. Although some authors have tried to use analysis of flow voids or signal voids in the choriocapillaris to quantify the area taken up by the microvasculature $[143,144]$, the data pertaining to myopic patients are but insufficient [145]. Looking into the future, there is, however, incipient research suggesting that the comprehension of blood supply and changes in vasculature from the anterior to the posterior segment of the myopic eye is crucial to the understanding of the disease [146-149].

Photoacoustic imaging has shown promise recently to fill the gaps between OCT and ultrasound in terms of penetration depth [150]. This modality has been used 
before to image the posterior pole of the eye in vitro and in animal models in vivo. This can also be used in concurrence with angiography, measuring oxygen saturation and pigment imaging [151]. However, there are some limitations pertaining to this modality notwithstanding moderate depth resolution, pure optical absorption sensing, need for contact detection with ultrasound sensor, and a relatively long acquisition time. In view of these limitations, we are yet to receive tangible results from photoacoustic imaging for posterior pole imaging in humans.

\subsection{Glaucoma in Myopia}

Axial myopization leads to marked changes of the optic nerve head: (1) an enlargement of all three layers of the optic disc (i.e., optic disc Bruch's membrane opening, optic disc choroidal opening, optic disc scleral opening) with the development of a secondary macrodisc, (2) an enlargement and shallowing of the cup, (3) an elongation and thinning of the lamina cribrosa with a secondary reduction in the distance between the intraocular space with the intraocular pressure (IOP) and the retro-lamina compartment with the orbital cerebrospinal fluid pressure, (4) a direct exposure of the peripheral posterior lamina cribrosa surface to the orbital cerebrospinal fluid space, (5) an elongation and thinning of the peripapillary scleral flange with development and enlargement of the parapapillary gamma zone and delta zone, (6) an elongation and thinning of the peripapillary border tissue of the choroid, and (7) a rotation of the optic disc around the vertical axis, and less often and to a minor degree around the horizontal axis und the sagittal axis. These changes make it more difficult to differentiate between myopic changes and (additional) glaucomaassociated changes such as a loss of neuroretinal rim and thinning of the retinal nerve fiber layer, and these changes may make the optic nerve head more vulnerable, potentially explaining the increased prevalence of glaucomatous optic neuropathy in highly myopic eyes.

Population-based investigations and hospital-based studies have shown that the prevalence of glaucomatous optic neuropathy (GON) was higher in highly myopic eyes than in emmetropic eyes [152-166]. A previous study revealed that at a given IOP in patients with chronic open-angle glaucoma, the amount of optic nerve damage was more marked in highly myopic eyes with large optic discs than in nonhighly myopic eyes [165].

Highly myopic glaucomatous eyes as compared with non-highly myopic glaucomatous eyes may have a markedly lower IOP threshold to develop optic nerve damage. It could indicate that an IOP of perhaps lower than $10 \mathrm{mmHg}$ might be necessary to prevent the development of GON in these highly myopic eyes, and that in highly myopic eyes with axial elongation-associated enlargement and stretching of the optic disc and parapapillary region as the main risk factors for GON in high myopia a normal IOP may be sufficient to lead to GON [136].

Although it has not yet been firmly proven that GON in high myopia is dependent on IOP, most researchers recommend lowering IOP in highly myopic patients with glaucoma. Based on the morphological findings described above, the target 
pressure in highly myopic glaucoma may be lower than in non-highly myopic glaucoma. Due to the peculiar anatomy of the optic nerve head in highly myopic eyes, most diagnostic procedures fail in precisely assessing the status of the optic nerve in highly myopic eyes with glaucoma. It includes factors such as a decreased spatial and color contrast between the neuroretinal rim and the optic cup making a delineation of both structures more difficult; a peripapillary retinoschisis leading to an incorrect segmentation of the retinal nerve fiber layer upon optical coherence tomography; a large gamma zone (and delta zone) which makes using the end of Bruch's membrane as reference point for the measurement of the neuroretinal rim useless; and macular Bruch's membrane defects and other reasons for nonglaucomatous visual field defects which reduces the diagnostic precision of perimetry for the detection of presence and progression of GON.

\subsection{Management of Myopic Choroidal Neovascularization}

Myopic choroidal neovascularization (myopic CNV) is the second most common cause of CNV after age-related macular degeneration (AMD) [167, 168]. It is one of the most sight-threatening complications of pathological myopia [119, 169] and is the most common cause of CNV in those 50 years or younger [167], with significant social and economic burden. The prevalence of myopic CNV is between $5.2 \%$ and $11.3 \%$ in individuals with pathological myopia [12], with female preponderance seen in most studies [167-170]. The long-term outcome of CNV is poor if left untreated. In a 10-year follow-up study of 25 patients with myopic CNV, visual acuity deteriorated to $20 / 200$ or worse in $89 \%$ and $96 \%$ of eyes in 5 years and 10 years, respectively [168].

On slit-lamp biomicroscopy, myopic CNV manifests as a small, flat, grayish subretinal lesion adjacent to or beneath the fovea $[109,168,169,171]$. On SD-OCT, myopic CNV presents as a hyper-reflective material above the retinal pigment epithelium band (type $2 \mathrm{CNV}$ ), with variable amount of subretinal fluid. Clinical diagnosis is confirmed by fundus fluorescein angiography (FFA). Most myopic CNVs are type 2 neovascularization and present with a "classic" pattern on FA. OCT angiography (OCTA) was able to detect flow within myopic CNV vascular complexes and hence delineate vascular networks in these myopic neovascular membranes that lie above the retinal pigment epithelium (RPE) where flow signals are spared from attenuation [172].

Prior to the advent of anti-VEGF therapy, the main treatment options for myopic CNV were limited to thermal laser photocoagulation [173], photodynamic therapy with verteporfin (vPDT) $[174,175]$. These treatments had limited efficacy in improving vision significantly and have now largely been relegated to the annals of history by anti-vascular endothelial growth factor (anti-VEGF) therapy [176]. Once active myopic CNV is diagnosed, prompt treatment with intravitreal anti-VEGF therapy should be administered as soon as possible [121, 177]. Current evidence suggests a pro-re-nata (PRN) regimen without a loading phase can be considered in most patients. Patients should be monitored monthly with OCT and treatment administered until cessation of disease activity on OCT or visual stabilization. 


\subsection{Management of Myopia-Related Retinal Complications}

Myopic traction maculopathy (MTM) [123] is estimated to occur in approximately $8-34 \%$ in individuals with high myopia [178-180] and encompasses retinal thickening, macular retinoschisis, foveal detachment, lamellar macular hole with or without epiretinal membrane and/or vitreomacular traction [123], and/ or full-thickness macular hole (HM) with or without retinal detachment. Central to the pathogenesis of MTM is traction, which was postulated to arise from one or more of the following mechanisms [181]: vitreomacular traction associated with perifoveal posterior vitreous detachment (PVD) [182-184]; relative incompliance of the internal limiting membrane (ILM) [185-189], epiretinal membrane (ERM) [180, 182, 190-192], and cortical vitreous remnant after PVD [193] to the outer retina which conforms to the shape of the posterior staphyloma; and traction exerted by retinal arterioles [188, 194, 195]. Not all patients with MTM require interventions [184, 196, 197]. There are numerous reported interventions for MTM. The principles of the treatment are: (1) to relieve traction, mainly achieved through pars plana vitrectomy (PPV) with or without ILM peeling; (2) to minimize surgical damage to the weakened macula through technique modifications in order to prevent the formation of postoperative $\mathrm{MH}$; and (3) in the presence of full-thickness $\mathrm{MH}$, to maximize the chance of hole closure through the use of various surgical adjuncts.

\subsubsection{Proposed Adjuncts to Improve Outcome of Macular Hole Surgery}

Inverted Internal Limiting Membrane Flap This technique involves leaving a hinge of ILM flap at the edge of MH during ILM peeling. This ILM flap is then inverted upside-down to cover or fill the $\mathrm{MH}$ [198].

Autologous Internal Limiting Membrane Transplantation In eyes where ILM around the macula hole has already been removed, an appropriately sized ILM can be peeled off from a distant site and placed as a free flap onto the persistent $\mathrm{MH}$ [199, 200].

Autologous Blood In order to prevent subretinal migration of dye and the resultant retinal toxicity associated with vital stains, it was proposed to use autologous blood to cover the $\mathrm{MH}$ before injection of brilliant blue dye. It has been demonstrated that compared to conventional method, the use of pre-staining autologous blood led to better visual acuity outcomes and continuity of ellipsoid zone at all post-operative time points [201].

Lens Capsular Flap Transplantation Chen et al. demonstrated a 100\% MH closure rate with anterior capsular transplantation among patients with refractory $\mathrm{MH}$, 


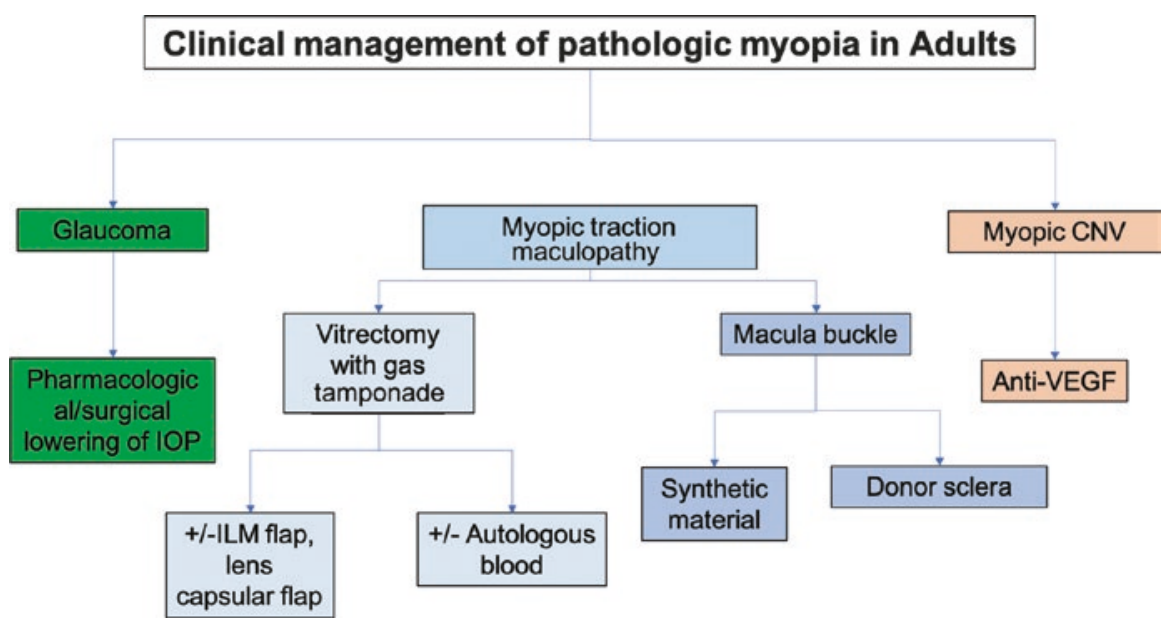

Fig. 1.1 Summary of the clinical management of pathologic myopia in adults

whereas the complete closure rate of $\mathrm{MH}$ after posterior capsular transplantation was only $50 \%$ and with another $30 \%$ enjoyed partial MH closure [202].

Macular Buckle Macular buckles have been used to shorten the axial length of myopic eyeballs in conditions such as macular hole retinal detachment (MHRD), myopic foveoschisis with or without foveal detachment, and $\mathrm{MH}$ with foveoschisis. There are many types of macular buckle, including scleral sponge, T-shaped or L-shaped buckle, Ando Plombe, wire-strengthened sponge exoplant, and even donor sclera and suprachoroidal injectable long-acting hyaluronic acid [203].

Autologous Neurosensory Retinal Transplantation The technique involves bimanually harvesting a free flap of neurosensory retina superior to the superotemporal arcade, with the harvest site first secured by endolaser barricade and endodiathermy. The free flap was translocated in its correct orientation over the macular hole and perfluoro- $n$-octane heavy liquid (PFC) was instilled over it, followed by direct PFC-silicone oil exchange [204].

Figure 1.1 presents an overview of the management of myopia-related complications in adults.

\subsection{Management and Control of Myopia in Children}

Currently, there are many types of interventions to slow myopia progression in children, including spectacle lenses, contact lenses, pharmaceuticals, and environmental or behavioral modification. However, none of these myopia control methods have been proven to stop the development or progression of myopia completely and each method has their own limitations. 
Spectacle Lenses Under-correction of myopia in clinical trials has shown conflicting results and small, clinically insignificant effect on slowing myopia progression [205-207]. In view of these conflicting results, there is no convincing evidence to indicate that under-correction should be used to slow myopia progression.

Bifocal or Multifocal Spectacles Most studies showed that progressive addition lenses (PALs) have an insignificant effect on slowing myopia progression rate (less than 0.2 D per year) overall [48, 208-214]. In contrast, a randomized, controlled trial showed that executive bifocal lenses slowed myopia progression in Chinese-Canadian children aged 8-13 years by $39 \%$ and up to $51 \%$ with basein prisms incorporated over 3 years [215]. More recently, the Defocus Incorporated Multiple Segments (DIMS) spectacle lens enabled clear vision and myopic defocus simultaneously for the wearer [216]. Hong Kong Chinese children aged 8-13 years wearing DIMS lenses had approximately 60\% less myopia progression and axial elongation when compared with children wearing single vision spectacle lenses over 2 years. Moreover, about $20 \%$ of the DIMS lens wearers had no myopia progression during the study period.

Peripheral Myopic Defocus Glasses In 2010, Sankaridurg et al. published their results of three novel peripheral defocus spectacle lens. Unfortunately, there was no significant effect on myopic progression with all three designs [217]. In a recent randomized controlled trial (RCT) conducted in Japanese children with peripheral defocus lenses, no difference in myopia reduction was found [218].

Rigid Gas Permeable Contact Lenses Two randomized clinical trials [219, 220] showed that rigid gas permeable (RGP) contact lenses did not retard axial eye growth. However, Walline et al. [219] reported significant slower myopia progression in the group of RGP lenses compared with soft contact lenses, despite that no differences were found in axial elongation between the groups. The proposed reason for a treatment effect on refraction may be due to the changes in corneal curvature.

Orthokeratology Orthokeratology (Ortho-K) lenses are specially designed RGP contact lenses that are worn overnight to reshape the cornea and thereby temporarily correct low-to-moderate myopia. Various clinical studies have demonstrated the effectiveness of inhibiting myopic progression with Ortho-K. Individual studies and meta-analyses have shown a $32-63 \%$ reduction in the rate of axial elongation in East Asian children initially aged from 7 to 16 years and followed for up to 5 years [221-227]. Efficacy may decrease over time [224, 228], with a potential "rebound" after discontinuation, especially in children under 14 years [229]. There is also a potential non-response rate of 7-12\% [223]. Interestingly, a recent study in Japan [230] showed that the combination of Ortho-K and low-concentration atropine $(0.01 \%)$ eyedrops was more effective in slowing axial elongation over 12 months than Ortho-K treatment alone in myopic children. The risk of infective keratitis remains [231]. 
Soft Bifocal and Multifocal Contact Lenses These lenses are worn during the daytime. Compared to spectacles, contact lenses are more cosmetically acceptable, more easily handled, and are more convenient for daily activities of some children, especially during sports $[232,233]$. For most of eye-care practitioners, the fitting procedures of soft bifocal contact lenses are relatively simpler than Ortho-K. Overall, soft bifocal and multifocal contact lenses slow the progression of myopia in children by an amount comparable to that of Ortho-K lenses. Studies exploring the effect of these bifocal soft contact lenses indicate slowing of myopia progression by $25-50 \%$ and axial length by $27-32 \%$ in children aged $8-16$ of various ethnicities over a period of 24 months [234, 235].

Atropine The initial high doses of atropine (i.e., 0.5\% or 1.0\%) slowed myopia progression by more than $70 \%$ in Asian children aged 6-13 years over 1-2 years [229, 236-238]. However, lower doses ( $0.1 \%$ or less) can also slow refractive progression by 30-60\% with less side effects (pupil dilation, glare, or blur) [238]. The Atropine Treatment of Myopia (ATOM) studies showed that there was a myopic rebound if atropine was stopped suddenly, especially at higher doses and in younger children $[239,240]$.

Time Spent Outdoors In the Sydney Myopia Study, exposure to more than $2 \mathrm{~h}$ of outdoor activity per day decreased the odds of myopia and countered the effects of near work [65]. Interventions involving increasing time outdoors appeared to reduce the onset of myopia and also its progression in myopic children [71]. A metaanalysis has suggested a $2 \%$ reduced odds of myopia per additional hour of time spent outdoors per week [70].

Environmental Interventions Based on new evidence, the advice has shifted from spending at least $2 \mathrm{~h}$ per day outdoors in addition to avoiding excessive near work. This has changed health and school messaging in many East Asian countries [71].

Higher Light Intensities and Dopamine Potential reasons why time outdoors may be protective include higher light intensities [241], differences in chromatic composition [242], the reduction in dioptric accommodative focus and psychometric influences encountered outdoors [243]. The role of chromaticity (red and blue) and ultraviolet (UV) light is still uncertain [244], while that of higher vitamin D levels has been debunked [88].

Figure 1.2 presents an overview of the management and prevention of myopia in children. 


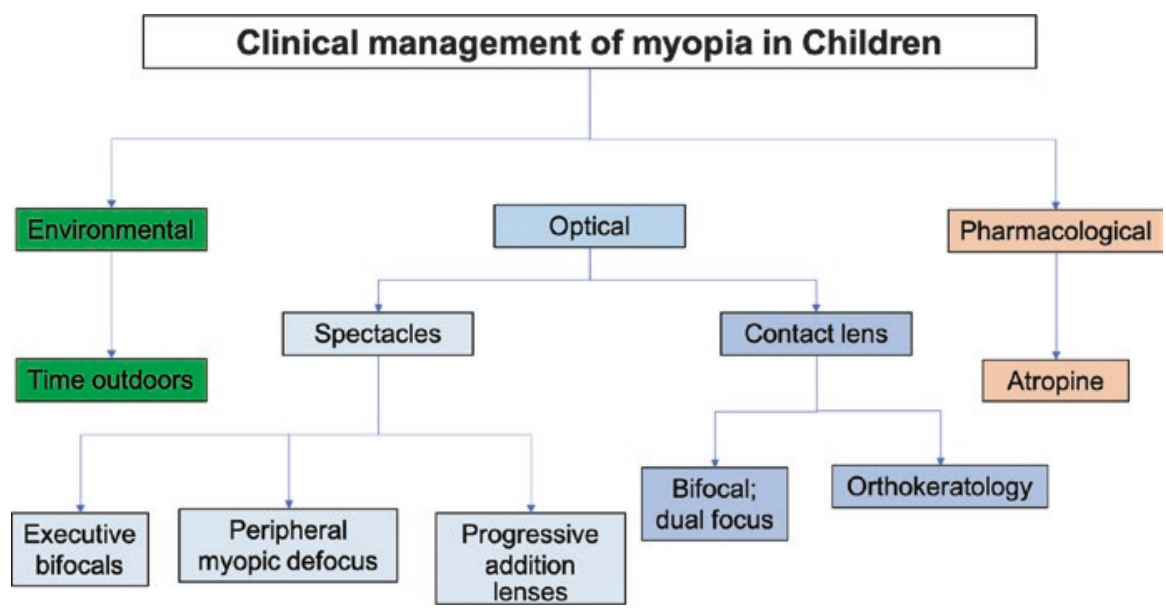

Fig. 1.2 Summary of the clinical management of myopia in children

\section{References}

1. Dolgin E. The myopia boom. Nature. 2015;519(7543):276-8.

2. Vitale S, Cotch MF, Sperduto RD. Prevalence of visual impairment in the United States. JAMA. 2006;295(18):2158-63.

3. Zheng YF, Pan CW, Chay J, Wong TY, Finkelstein E, Saw SM. The economic cost of myopia in adults aged over 40 years in Singapore. Invest Ophthalmol Vis Sci. 2013;54(12):7532-7.

4. Liang YB, Wong TY, Sun LP, et al. Refractive errors in a rural Chinese adult population the Handan eye study. Ophthalmology. 2009;116(11):2119-27.

5. Morgan IG, Ohno-Matsui K, Saw S-M. Myopia. Lancet. 2012;379(9827):1739-48.

6. Morgan IG. What public policies should be developed to deal with the epidemic of myopia? Optom Vis Sci. 2016;93(9):1058-60.

7. Lin LL, Shih YF, Hsiao CK, Chen CJ. Prevalence of myopia in Taiwanese school children: 1983 to 2000. Ann Acad Med Singap. 2004;33(1):27-33.

8. Jung SK, Lee JH, Kakizaki H, Jee D. Prevalence of myopia and its association with body stature and educational level in 19-year-old male conscripts in Seoul, South Korea. Invest Ophthalmol Vis Sci. 2012;53(9):5579-83.

9. Holden BA, Fricke TR, Wilson DA, et al. Global prevalence of myopia and high myopia and temporal trends from 2000 through 2050. Ophthalmology. 2016;123(5):1036-42.

10. Ding BY, Shih YF, Lin LLK, Hsiao CK, Wang IJ. Myopia among school children in East Asia and Singapore. Surv Ophthalmol. 2017;62(5):677-97.

11. Wong YL, Sabanayagam C, Ding Y, et al. Prevalence, risk factors, and impact of myopic macular degeneration on visual impairment and functioning among adults in Singapore. Invest Ophthalmol Vis Sci. 2018;59(11):4603-13. 
12. Wong TY, Ferreira A, Hughes R, Carter G, Mitchell P. Epidemiology and disease burden of pathologic myopia and myopic choroidal neovascularization: an evidence-based systematic review. Am J Ophthalmol. 2014;157(1):9-25 e12.

13. Xie R, Zhou XT, Lu F, et al. Correlation between myopia and major biometric parameters of the eye: a retrospective clinical study. Optom Vis Sci. 2009;86(5):E503-8.

14. Li SM, Li SY, Kang MT, et al. Distribution of ocular biometry in 7- and 14-year-old Chinese children. Optom Vis Sci. 2015;92(5):566-72.

15. Richter GM, Wang M, Jiang X, et al. Ocular determinants of refractive error and its age- and sex-related variations in the Chinese American eye study. JAMA Ophthalmol. 2017;135(7):724-32.

16. Read SA, Collins MJ, Vincent SJ, Alonso-Caneiro D. Choroidal thickness in myopic and nonmyopic children assessed with enhanced depth imaging optical coherence tomography. Invest Ophthalmol Vis Sci. 2013;54(12):7578-86.

17. Xiong S, He X, Deng J, et al. Choroidal thickness in 3001 Chinese children aged 6 to 19 years using swept-source OCT. Sci Rep. 2017;7:45059.

18. Chen FK, Yeoh J, Rahman W, Patel PJ, Tufail A, Da Cruz L. Topographic variation and interocular symmetry of macular choroidal thickness using enhanced depth imaging optical coherence tomography. Invest Ophthalmol Vis Sci. 2012;53(2):975-85.

19. Esmaeelpour M, Povazay B, Hermann B, et al. Three-dimensional 1060-nm OCT: choroidal thickness maps in normal subjects and improved posterior segment visualization in cataract patients. Invest Ophthalmol Vis Sci. 2010;51(10):5260-6.

20. Gupta P, Jing T, Marziliano P, et al. Distribution and determinants of choroidal thickness and volume using automated segmentation software in a population-based study. Am J Ophthalmol. 2015;159(2):293-301.e293.

21. Li XQ, Munkholm A, Larsen M, Munch IC. Choroidal thickness in relation to birth parameters in 11- to 12-year-old children: the Copenhagen child cohort 2000 eye study. Invest Ophthalmol Vis Sci. 2014;56(1):617-24.

22. Ouyang Y, Heussen FM, Mokwa N, et al. Spatial distribution of posterior pole choroidal thickness by spectral domain optical coherence tomography. Invest Ophthalmol Vis Sci. 2011;52(9):7019-26.

23. Tan CS, Cheong KX. Macular choroidal thicknesses in healthy adults--relationship with ocular and demographic factors. Invest Ophthalmol Vis Sci. 2014;55(10):6452-8.

24. Wei WB, Xu L, Jonas JB, et al. Subfoveal choroidal thickness: the Beijing eye study. Ophthalmology. 2013;120(1):175-80.

25. Sanchez-Cano A, Orduna E, Segura F, et al. Choroidal thickness and volume in healthy young white adults and the relationships between them and axial length, ammetropy and sex. Am J Ophthalmol. 2014;158(3):574-583.e571.

26. He X, Jin P, Zou H, et al. Choroidal thickness in healthy Chinese children aged 6 to 12: the Shanghai children eye study. Retina. 2017;37(2):368-75.

27. Jin P, Zou H, Zhu J, et al. Choroidal and retinal thickness in children with different refractive status measured by swept-source optical coherence tomography. Am J Ophthalmol. 2016;168:164-76.

28. Zhang JM, Wu JF, Chen JH, et al. Macular choroidal thickness in children: the Shandong children eye study. Invest Ophthalmol Vis Sci. 2015;56(13):7646-52.

29. Zhou LX, Shao L, Xu L, Wei WB, Wang YX, You QS. The relationship between scleral staphyloma and choroidal thinning in highly myopic eyes: the Beijing eye study. Sci Rep. 2017;7(1):9825.

30. Wang NK, Lai CC, Chou CL, et al. Choroidal thickness and biometric markers for the screening of lacquer cracks in patients with high myopia. PLoS One. 2013;8(1):e53660.

31. Ikuno Y, Jo Y, Hamasaki T, Tano Y. Ocular risk factors for choroidal neovascularization in pathologic myopia. Invest Ophthalmol Vis Sci. 2010;51(7):3721-5.

32. Nishida Y, Fujiwara T, Imamura Y, Lima LH, Kurosaka D, Spaide RF. Choroidal thickness and visual acuity in highly myopic eyes. Retina. 2012;32(7):1229-36. 
33. Read SA, Alonso-Caneiro D, Vincent SJ, Collins MJ. Longitudinal changes in choroidal thickness and eye growth in childhood. Invest Ophthalmol Vis Sci. 2015;56(5):3103-12.

34. Fontaine M, Gaucher D, Sauer A, Speeg-Schatz C. Choroidal thickness and ametropia in children: a longitudinal study. Eur J Ophthalmol. 2017;27:730-4.

35. Jin $\mathrm{P}, \mathrm{Zou} \mathrm{H}, \mathrm{Xu} \mathrm{X}$, et al. Longitudinal changes in choroidal and retinal thicknesses in children with myopic shift. Retina. 2018. https://doi.org/10.1097/IAE.0000000000002090.

36. Chen Z, Xue F, Zhou J, Qu X, Zhou X. Effects of orthokeratology on choroidal thickness and axial length. Optom Vis Sci. 2016;93(9):1064-71.

37. Li Z, Cui D, Hu Y, Ao S, Zeng J, Yang X. Choroidal thickness and axial length changes in myopic children treated with orthokeratology. Cont Lens Anterior Eye. 2017;40(6): 417-23.

38. Sander BP, Collins MJ, Read SA. The effect of topical adrenergic and anticholinergic agents on the choroidal thickness of young healthy adults. Exp Eye Res. 2014;128:181-9.

39. Zhang Z, Zhou Y, Xie Z, et al. The effect of topical atropine on the choroidal thickness of healthy children. Sci Rep. 2016;6:34936.

40. Read SA. Ocular and environmental factors associated with eye growth in childhood. Optom Vis Sci. 2016;93(9):1031-41.

41. Charman WN. Aberrations and myopia. Ophthalmic Physiol Opt. 2005;25(4):285-301.

42. Little JA, McCullough SJ, Breslin KM, Saunders KJ. Higher order ocular aberrations and their relation to refractive error and ocular biometry in children. Invest Ophthalmol Vis Sci. 2014;55(8):4791-800.

43. Buehren T, Collins MJ, Carney LG. Near work induced wavefront aberrations in myopia. Vis Res. 2005;45(10):1297-312.

44. Vincent SJ, Collins MJ, Read SA, Carney LG, Yap MK. Corneal changes following near work in myopic anisometropia. Ophthalmic Physiol Opt. 2013;33(1):15-25.

45. Lau JK, Vincent SJ, Collins MJ, Cheung SW, Cho P. Ocular higher-order aberrations and axial eye growth in young Hong Kong children. Sci Rep. 2018;8(1):6726.

46. Hiraoka T, Kotsuka J, Kakita T, Okamoto F, Oshika T. Relationship between higher-order wavefront aberrations and natural progression of myopia in schoolchildren. Sci Rep. 2017;7(1):7876.

47. Huang HM, Chang DS, Wu PC. The association between near work activities and myopia in children-a systematic review and meta-analysis. PLoS One. 2015;10(10):e0140419.

48. Gwiazda J, Hyman L, Hussein M, et al. A randomized clinical trial of progressive addition lenses versus single vision lenses on the progression of myopia in children. Invest Ophthalmol Vis Sci. 2003;44(4):1492-500.

49. Cheng D, Schmid KL, Woo GC, Drobe B. Randomized trial of effect of bifocal and prismatic bifocal spectacles on myopic progression: two-year results. Arch Ophthalmol. 2010;128(1):12-9.

50. Berntsen DA, Barr CD, Mutti DO, Zadnik K. Peripheral defocus and myopia progression in myopic children randomly assigned to wear single vision and progressive addition lenses. Invest Ophthalmol Vis Sci. 2013;54(8):5761-70.

51. Mutti DO, Mitchell GL, Hayes JR, et al. Accommodative lag before and after the onset of myopia. Invest Ophthalmol Vis Sci. 2006;47(3):837-46.

52. Nickels S, Hopf S, Pfeiffer N, Schuster AK. Myopia is associated with education: results from NHANES 1999-2008. PLoS One. 2019;14(1):e0211196.

53. Mountjoy E, Davies NM, Plotnikov D, et al. Education and myopia: assessing the direction of causality by mendelian randomisation. BMJ. 2018;361:k2022.

54. Morgan IG, French AN, Ashby RS, et al. The epidemics of myopia: aetiology and prevention. Prog Retin Eye Res. 2018;62:134-49.

55. Cuellar-Partida G, Lu Y, Kho PF, et al. Assessing the genetic predisposition of education on myopia: a mendelian randomization study. Genet Epidemiol. 2016;40(1):66-72.

56. Williams KM, Bertelsen G, Cumberland P, et al. Increasing prevalence of myopia in Europe and the impact of education. Ophthalmology. 2015;122(7):1489-97. 
57. Han SB, Jang J, Yang HK, Hwang JM, Park SK. Prevalence and risk factors of myopia in adult Korean population: Korea national health and nutrition examination survey 2013-2014 (KNHANES VI). PLoS One. 2019;14(1):e0211204.

58. Gwiazda J, Thorn F, Bauer J, Held R. Myopic children show insufficient accommodative response to blur. Invest Ophthalmol Vis Sci. 1993;34(3):690-4.

59. Read SA, Collins MJ, Woodman EC, Cheong SH. Axial length changes during accommodation in myopes and emmetropes. Optom Vis Sci. 2010;87(9):656-62.

60. Woodman-Pieterse EC, Read SA, Collins MJ, Alonso-Caneiro D. Regional changes in choroidal thickness associated with accommodation. Invest Ophthalmol Vis Sci. 2015;56(11):6414-22.

61. Hepsen IF, Evereklioglu C, Bayramlar H. The effect of reading and near-work on the development of myopia in emmetropic boys: a prospective, controlled, three-year follow-up study. Vis Res. 2001;41(19):2511-20.

62. Jones LA, Sinnott LT, Mutti DO, Mitchell GL, Moeschberger ML, Zadnik K. Parental history of myopia, sports and outdoor activities, and future myopia. Invest Ophthalmol Vis Sci. 2007;48(8):3524-32.

63. Mutti DO, Mitchell GL, Moeschberger ML, Jones LA, Zadnik K. Parental myopia, near work, school achievement, and children's refractive error. Invest Ophthalmol Vis Sci. 2002;43(12):3633-40.

64. Parssinen O, Lyyra AL. Myopia and myopic progression among school children: a three-year follow-up study. Invest Ophthalmol Vis Sci. 1993;34(9):2794-802.

65. Rose KA, Morgan IG, Ip J, et al. Outdoor activity reduces the prevalence of myopia in children. Ophthalmology. 2008;115(8):1279-85.

66. Guo Y, Liu LJ, Tang P, et al. Outdoor activity and myopia progression in 4-year followup of Chinese primary school children: The Beijing Children Eye Study. PLoS One. 2017;12(4):e0175921.

67. Guggenheim JA, Northstone K, McMahon G, et al. Time outdoors and physical activity as predictors of incident myopia in childhood: a prospective cohort study. Invest Ophthalmol Vis Sci. 2012;53(6):2856-65.

68. Parssinen O, Kauppinen M, Viljanen A. The progression of myopia from its onset at age 8-12 to adulthood and the influence of heredity and external factors on myopic progression. A 23-year follow-up study. Acta Ophthalmol. 2014;92(8):730-9.

69. Jones-Jordan LA, Sinnott LT, Cotter SA, et al. Time outdoors, visual activity, and myopia progression in juvenile-onset myopes. Invest Ophthalmol Vis Sci. 2012;53(11):7169-75.

70. Sherwin JC, Reacher MH, Keogh RH, Khawaja AP, Mackey DA, Foster PJ. The association between time spent outdoors and myopia in children and adolescents: a systematic review and meta-analysis. Ophthalmology. 2012;119(10):2141-51.

71. Wu PC, Chen CT, Lin KK, et al. Myopia prevention and outdoor light intensity in a schoolbased cluster randomized trial. Ophthalmology. 2018;125:1239-50.

72. He M, Xiang F, Zeng Y, et al. Effect of time spent outdoors at school on the development of myopia among children in China: a randomized clinical trial. JAMA. 2015;314(11):1142-8.

73. Wu PC, Tsai CL, Wu HL, Yang YH, Kuo HK. Outdoor activity during class recess reduces myopia onset and progression in school children. Ophthalmology. 2013;120(5):1080-5.

74. Read SA, Collins MJ, Vincent SJ. Light exposure and eye growth in childhood. Invest Ophthalmol Vis Sci. 2015;56(11):6779-87.

75. Metlapally R, Li YJ, Tran-Viet KN, et al. COL1A1 and COL2A1 genes and myopia susceptibility: evidence of association and suggestive linkage to the COL2A1 locus. Invest Ophthalmol Vis Sci. 2009;50(9):4080-6.

76. Mutti DO, Cooper ME, O’Brien S, et al. Candidate gene and locus analysis of myopia. Mol Vis. 2007;13:1012-9.

77. Hall NF, Gale CR, Ye S, Martyn CN. Myopia and polymorphisms in genes for matrix metalloproteinases. Invest Ophthalmol Vis Sci. 2009;50(6):2632-6.

78. Wojciechowski R, Yee SS, Simpson CL, Bailey-Wilson JE, Stambolian D. Matrix metalloproteinases and educational attainment in refractive error: evidence of gene-environment interactions in the age-related eye disease study. Ophthalmology. 2013;120(2):298-305. 
79. Tang SM, Rong SS, Young AL, Tam PO, Pang CP, Chen LJ. PAX6 gene associated with high myopia: a meta-analysis. Optom Vis Sci. 2014;91(4):419-29.

80. Tedja MS, Wojciechowski R, Hysi PG, et al. Genome-wide association meta-analysis highlights light-induced signaling as a driver for refractive error. Nat Genet. 2018;50(6):834-48.

81. Wojciechowski R, Bailey-Wilson JE, Stambolian D. Association of matrix metalloproteinase gene polymorphisms with refractive error in Amish and Ashkenazi families. Invest Ophthalmol Vis Sci. 2010;51(10):4989-95.

82. Fan Q, Wojciechowski R, Kamran Ikram M, et al. Education influences the association between genetic variants and refractive error: a meta-analysis of five Singapore studies. Hum Mol Genet. 2014;23(2):546-54.

83. Verhoeven VJ, Buitendijk GH, Consortium for Refractive E, et al. Education influences the role of genetics in myopia. Eur J Epidemiol. 2013;28(12):973-80.

84. Fan Q, Guo X, Tideman JW, et al. Childhood gene-environment interactions and agedependent effects of genetic variants associated with refractive error and myopia: The CREAM Consortium. Sci Rep. 2016;6:25853.

85. Fan Q, Verhoeven VJ, Wojciechowski R, et al. Meta-analysis of gene-environment-wide association scans accounting for education level identifies additional loci for refractive error. Nat Commun. 2016;7:11008.

86. Ebrahim S, Davey Smith G. Mendelian randomization: can genetic epidemiology help redress the failures of observational epidemiology? Hum Genet. 2008;123(1):15-33.

87. Smith GD, Ebrahim S. Mendelian randomization: prospects, potentials, and limitations. Int J Epidemiol. 2004;33(1):30-42.

88. Cuellar-Partida G, Williams KM, Yazar S, et al. Genetically low vitamin D concentrations and myopic refractive error: a Mendelian randomization study. Int J Epidemiol. 2017;46(6):1882-90.

89. Ghorbani Mojarrad N, Williams C, Guggenheim JA. A genetic risk score and number of myopic parents independently predict myopia. Ophthalmic Physiol Opt. 2018;38(5):492-502.

90. Zhao J, Mao J, Luo R, Li F, Munoz SR, Ellwein LB. The progression of refractive error in school-age children: Shunyi district, China. Am J Ophthalmol. 2002;134(5):735-43.

91. Xiang F, He M, Zeng Y, Mai J, Rose KA, Morgan IG. Increases in the prevalence of reduced visual acuity and myopia in Chinese children in Guangzhou over the past 20 years. Eye. 2013;27(12):1353-8.

92. Wang SK, Guo Y, Liao C, et al. Incidence of and factors associated with myopia and high myopia in Chinese children, based on refraction without cycloplegia. JAMA Ophthalmol. 2018;136(9):1017-24.

93. Saw SM, Tong L, Chua WH, et al. Incidence and progression of myopia in Singaporean school children. Invest Ophthalmol Vis Sci. 2005;46(1):51-7.

94. Matsumura H, Hirai H. Prevalence of myopia and refractive changes in students from 3 to 17 years of age. Surv Ophthalmol. 1999;44(Suppl 1):S109-15.

95. Tsai DC, Fang SY, Huang N, et al. Myopia development among young school children: the myopia investigation study in Taipei. Invest Ophthalmol Vis Sci. 2016;57(15):6852-60.

96. Xiang F, He M, Morgan IG. Annual changes in refractive errors and ocular components before and after the onset of myopia in Chinese children. Ophthalmology. 2012;119(7):1478-84.

97. COMET Group. Myopia stabilization and associated factors among participants in the Correction of Myopia Evaluation Trial (COMET). Invest Ophthalmol Vis Sci. 2013;54(13):7871-84.

98. French AN, Morgan IG, Burlutsky G, Mitchell P, Rose KA. Prevalence and 5- to 6-year incidence and progression of myopia and hyperopia in Australian schoolchildren. Ophthalmology. 2013;120(7):1482-91.

99. Jones-Jordan LA, Sinnott LT, Manny RE, et al. Early childhood refractive error and parental history of myopia as predictors of myopia. Invest Ophthalmol Vis Sci. 2010;51(1):115-21.

100. Williams C, Miller LL, Gazzard G, Saw SM. A comparison of measures of reading and intelligence as risk factors for the development of myopia in a UK cohort of children. Br J Ophthalmol. 2008;92(8):1117-21. 
101. Dirani M, Tong L, Gazzard G, et al. Outdoor activity and myopia in Singapore teenage children. Br J Ophthalmol. 2009;93(8):997.

102. Morgan IG. New perspectives on the prevention of myopia. Eye Sci. 2011;26(1):3.

103. Iwase A, Araie M, Tomidokoro A, et al. Prevalence and causes of low vision and blindness in a Japanese adult population: the Tajimi Study. Ophthalmology. 2006;113(8):1354-62.

104. Xu L, Wang Y, Li Y, Cui T, Li J, Jonas JB. Causes of blindness and visual impairment in urban and rural areas in Beijing: the Beijing Eye Study. Ophthalmology. 2006;113(7):1134 e1131-11.

105. You QS, Xu L, Yang H, Wang YX, Jonas JB. Five-year incidence of visual impairment and blindness in adult Chinese the Beijing Eye Study. Ophthalmology. 2011;118(6):1069-75.

106. Yamada M, Hiratsuka Y, Roberts CB, et al. Prevalence of visual impairment in the adult Japanese population by cause and severity and future projections. Ophthalmic Epidemiol. 2010;17(1):50-7.

107. Hsu WM, Cheng CY, Liu JH, Tsai SY, Chou P. Prevalence and causes of visual impairment in an elderly Chinese population in Taiwan: the Shihpai Eye Study. Ophthalmology. 2004;111(1):62-9.

108. Ohno-Matsui K, Lai TYY, Cheung CMG, Lai CC. Updates of pathologic myopia. Prog Retin Eye Res. 2016;52(5):156-87.

109. Ohno-Matsui K, Kawasaki R, Jonas JB, et al. International photographic classification and grading system for myopic maculopathy. Am J Ophthalmol. 2015;159(5):877-883 e877.

110. Spaide RF. Staphyloma: part 1. New York: Springer; 2014.

111. Fang Y, Yokoi T, Nagaoka N, et al. Progression of myopic maculopathy during 18-year follow-up. Ophthalmology. 2018;125:863-77.

112. Hayashi K, Ohno-Matsui K, Shimada N, et al. Long-term pattern of progression of myopic maculopathy: a natural history study. Ophthalmology. 2010;117(8):1595-611.

113. Yan YN, Wang YX, Yang Y, et al. Ten-year progression of myopic maculopathy: The Beijing Eye Study 2001-2011. Ophthalmology. 2018;125:1253-63.

114. Vongphanit J, Mitchell P, Wang JJ. Prevalence and progression of myopic retinopathy in an older population. Ophthalmology. 2002;109(4):704-11.

115. Xu L, Wang Y, Wang S, Jonas JB. High myopia and glaucoma susceptibility the Beijing Eye Study. Ophthalmology. 2007;114(2):216-20.

116. Nagaoka N, Jonas JB, Morohoshi K, et al. Glaucomatous-type optic discs in high myopia. PLoS One. 2015;10(10):e0138825.

117. Curtin BJ. The posterior staphyloma of pathologic myopia. Trans Am Ophthalmol Soc. 1977;75:67-86.

118. Ohno-Matsui K. Proposed classification of posterior staphylomas based on analyses of eye shape by three-dimensional magnetic resonance imaging. Ophthalmology. 2014;121(9):1798-809.

119. Neelam K, Cheung CM, Ohno-Matsui K, Lai TY, Wong TY. Choroidal neovascularization in pathological myopia. Prog Retin Eye Res. 2012;31(5):495-525.

120. Ohno-Matsui K, Yoshida T, Futagami S, et al. Patchy atrophy and lacquer cracks predispose to the development of choroidal neovascularisation in pathological myopia. Br J Ophthalmol. 2003;87(5):570-3.

121. Wolf S, Balciuniene VJ, Laganovska G, et al. RADIANCE: a randomized controlled study of ranibizumab in patients with choroidal neovascularization secondary to pathologic myopia. Ophthalmology. 2014;121(3):682-92.

122. Ikuno Y, Ohno-Matsui K, Wong TY, et al. Intravitreal aflibercept injection in patients with myopic choroidal neovascularization: The MYRROR Study. Ophthalmology. 2015;122(6):1220-7.

123. Panozzo G, Mercanti A. Optical coherence tomography findings in myopic traction maculopathy. Arch Ophthalmol. 2004;122(10):1455-60.

124. Gaucher D, Erginay A, Lecleire-Collet A, et al. Dome-shaped macula in eyes with myopic posterior staphyloma. Am J Ophthalmol. 2008;145(5):909-14. 
125. Caillaux V, Gaucher D, Gualino V, Massin P, Tadayoni R, Gaudric A. Morphologic characterization of dome-shaped macula in myopic eyes with serous macular detachment. Am J Ophthalmol. 2013;156(5):958-67.

126. Ellabban AA, Tsujikawa A, Matsumoto A, et al. Three-dimensional tomographic features of dome-shaped macula by swept-source optical coherence tomography. Am J Ophthalmol. 2012;3(12):578.

127. Imamura Y, Iida T, Maruko I, Zweifel SA, Spaide RF. Enhanced depth imaging optical coherence tomography of the sclera in dome-shaped macula. Am J Ophthalmol. 2011;151(2):297-302.

128. Pope JM, Verkicharla PK, Sepehrband F, Suheimat M, Schmid KL, Atchison DA. Threedimensional MRI study of the relationship between eye dimensions, retinal shape and myopia. Biomed Opt Express. 2017;8(5):2386-95.

129. Kuo AN, Verkicharla PK, McNabb RP, et al. Posterior eye shape measurement with retinal OCT compared to MRI. Invest Ophthalmol Vis Sci. 2016;57(9):196-203.

130. Samarawickrama C, Mitchell P, Tong L, et al. Myopia-related optic disc and retinal changes in adolescent children from singapore. Ophthalmology. 2011;118(10):2050-7.

131. Jonas JB, Jonas SB, Jonas RA, Holbach L, Panda-Jonas S. Histology of the parapapillary region in high myopia. Am J Ophthalmol. 2011;152(6):1021-9.

132. Park HY, Lee K, Park CK. Optic disc torsion direction predicts the location of glaucomatous damage in normal-tension glaucoma patients with myopia. Ophthalmology. 2012;119(9):1844-51.

133. Marcus MW, de Vries MM, Junoy Montolio FG, Jansonius NM. Myopia as a risk factor for open-angle glaucoma: a systematic review and meta-analysis. Ophthalmology. 2011;118(10):1989-1994.e1982.

134. Chang RT, Singh K. Myopia and glaucoma: diagnostic and therapeutic challenges. Curr Opin Ophthalmol. 2013;24(2):96-101.

135. Jonas JB, Gusek GC, Naumann GO. Optic disk morphometry in high myopia. Graefes Arch Clin Exp Ophthalmol. 1988;226(6):587-90.

136. Jonas JB, Nagaoka N, Fang YX, Weber P, Ohno-Matsui K. Intraocular pressure and glaucomatous optic neuropathy in high myopia. Invest Ophthalmol Vis Sci. 2017;58(13):5897-906.

137. Ohno-Matsui K, Shimada N, Yasuzumi K, et al. Long-term development of significant visual field defects in highly myopic eyes. Am J Ophthalmol. 2011;152(2):256-265 e251.

138. Han JC, Lee EJ, Kim SB, Kee C. The Characteristics of deep optic nerve head morphology in myopic normal tension glaucoma. Invest Ophthalmol Vis Sci. 2017;58(5):2695-704.

139. Johnson MW. Myopic traction maculopathy: pathogenic mechanisms and surgical treatment. Retina. 2012;32(Suppl 2):S205-10.

140. Wong CW, Phua V, Lee SY, Wong TY, Cheung CM. Is Choroidal or scleral thickness related to myopic macular degeneration? Invest Ophthalmol Vis Sci. 2017;58(2):907-13.

141. Ohno-Matsui K, Akiba M, Modegi T, et al. Association between shape of sclera and myopic retinochoroidal lesions in patients with pathologic myopia. Invest Ophthalmol Vis Sci. 2012;53(10):6046-61.

142. Shinohara K, Moriyama M, Shimada N, Yoshida T, Ohno-Matsui K. Characteristics of peripapillary staphylomas associated with high myopia determined by swept-source optical coherence tomography. Am J Ophthalmol. 2016;169:138-44.

143. Spaide RF. Choriocapillaris flow features follow a power law distribution: implications for characterization and mechanisms of disease progression. Am J Ophthalmol. 2016;170:58-67.

144. Zhang Q, Zheng F, Motulsky EH, et al. A novel strategy for quantifying choriocapillaris flow voids using swept-source OCT angiography. Invest Ophthalmol Vis Sci. 2018;59(1):203-11.

145. Al-Sheikh M, Phasukkijwatana N, Dolz-Marco R, et al. Quantitative OCT angiography of the retinal microvasculature and the choriocapillaris in myopic eyes. Invest Ophthalmol Vis Sci. 2017;58(4):2063-9.

146. Ang M, Devarajan K, Das S, et al. Comparison of anterior segment optical coherence tomography angiography systems for corneal vascularisation. Br J Ophthalmol. 2018;102(7):873-7. 
147. Cai Y, Alio Del Barrio JL, Wilkins MR, Ang M. Serial optical coherence tomography angiography for corneal vascularization. Graefes Arch Clin Exp Ophthalmol. 2017;255(1):135-9.

148. Ang M, Cai Y, Shahipasand S, et al. En face optical coherence tomography angiography for corneal neovascularisation. Br J Ophthalmol. 2016;100(5):616-21.

149. Grudzinska E, Modrzejewska M. Modern diagnostic techniques for the assessment of ocular blood flow in myopia: current state of knowledge. J Ophthalmol. 2018;2018:8.

150. Silverman RH, Cannata J, Shung KK, et al. $75 \mathrm{MHz}$ ultrasound biomicroscopy of anterior segment of eye. Ultrason Imaging. 2006;28(3):179-88.

151. Xie D, Li Q, Gao Q, Song W, Zhang HF, Yuan X. In vivo blind-deconvolution photoacoustic ophthalmoscopy with total variation regularization. J Biophotonics. 2018;11(9):e201700360.

152. Xu L, Wang Y, Wang S, Wang Y, Jonas JB. High myopia and glaucoma susceptibility the Beijing Eye Study. Ophthalmology. 2007;114(2):216-20.

153. Podos SM, Becker B, Morton WR. High myopia and primary open-angle glaucoma. Am J Ophthalmol. 1966;62(6):1038-43.

154. Greve EL, Furuno F. Myopia and glaucoma. Albrecht Von Graefes Arch Klin Exp Ophthalmol. 1980;213(1):33-41.

155. Daubs JG, Crick RP. Effect of refractive error on the risk of ocular hypertension and open angle glaucoma. Trans Ophthalmol Soc Aust. 1981;101(1):121-6.

156. Phelps CD. Effect of myopia on prognosis in treated primary open-angle glaucoma. Am J Ophthalmol. 1982;93(5):622-8.

157. Perkins ES, Phelps CD. Open angle glaucoma, ocular hypertension, low-tension glaucoma, and refraction. Arch Ophthalmol. 1982;100(9):1464-7.

158. Leske MC, Connell AM, Wu SY, Hyman LG, Schachat AP. Risk factors for open-angle glaucoma. The Barbados Eye Study. Arch Ophthalmol. 1995;113(7):918-24.

159. Chihara E, Liu X, Dong J, et al. Severe myopia as a risk factor for progressive visual field loss in primary open-angle glaucoma. Ophthalmologica. 1997;211(2):66-71.

160. Mitchell P, Hourihan F, Sandbach J, Wang JJ. The relationship between glaucoma and myopia: the Blue Mountains Eye Study. Ophthalmology. 1999;106(10):2010-5.

161. Grodum K, Heijl A, Bengtsson B. Refractive error and glaucoma. Acta Ophthalmol Scand. 2001;79(6):560-6.

162. Jonas JB, Martus P, Budde WM. Anisometropia and degree of optic nerve damage in chronic open-angle glaucoma. Am J Ophthalmol. 2002;134(4):547-51.

163. Wong TY, Klein BE, Klein R, Knudtson M, Lee KE. Refractive errors, intraocular pressure, and glaucoma in a white population. Ophthalmology. 2003;110(1):211-7.

164. Leske MC, Heijl A, Hussein M, et al. Factors for glaucoma progression and the effect of treatment: the early manifest glaucoma trial. Arch Ophthalmol. 2003;121(1):48-56.

165. Jonas JB, Budde WM. Optic nerve damage in highly myopic eyes with chronic open-angle glaucoma. Eur J Ophthalmol. 2005;15(1):41-7.

166. Kuzin AA, Varma R, Reddy HS, Torres M, Azen SP, Los Angeles Latino Eye Study G. Ocular biometry and open-angle glaucoma: the Los Angeles Latino Eye Study. Ophthalmology. 2010;117(9):1713-9.

167. Cohen SY, Laroche A, Leguen Y, Soubrane G, Coscas GJ. Etiology of choroidal neovascularization in young patients. Ophthalmology. 1996;103(8):1241-4.

168. Yoshida T, Ohno-Matsui K, Yasuzumi K, et al. Myopic choroidal neovascularization: a 10-year follow-up. Ophthalmology. 2003;110(7):1297-305.

169. Avila MP, Weiter JJ, Jalkh AE, Trempe CL, Pruett RC, Schepens CL. Natural history of choroidal neovascularization in degenerative myopia. Ophthalmology. 1984;91(12):1573-81.

170. Curtin BJ, Karlin DB. Axial length measurements and fundus changes of the myopic eye. I. The posterior fundus. Trans Am Ophthalmol Soc. 1970;68:312-34.

171. Lai TY, Cheung CM. Myopic choroidal neovascularization: diagnosis and treatment. Retina. 2016;36(9):1614-21.

172. Jia Y, Bailey ST, Wilson DJ, et al. Quantitative optical coherence tomography angiography of choroidal neovascularization in age-related macular degeneration. Ophthalmology. 2014;121(7):1435-44. 
173. Virgili G, Menchini F. Laser photocoagulation for choroidal neovascularisation in pathologic myopia. Cochrane Database Syst Rev. 2005;4:CD004765.

174. Blinder KJ, Blumenkranz MS, Bressler NM, et al. Verteporfin therapy of subfoveal choroidal neovascularization in pathologic myopia: 2-year results of a randomized clinical trial--VIP report no. 3. Ophthalmology. 2003;110(4):667-73.

175. Verteporfin in Photodynamic Therapy Study G. Photodynamic therapy of subfoveal choroidal neovascularization in pathologic myopia with verteporfin. 1-year results of a randomized clinical trial--VIP report no. 1. Ophthalmology. 2001;108(5):841-52.

176. Chen Y, Sharma T, Li X, et al. Ranibizumab versus verteporfin photodynamic therapy in Asian patients with myopic choroidal neovascularization: brilliance, a 12-month, randomized, double-masked study. Retina. 2018. https://doi.org/10.1097/IAE.0000000000002292.

177. Tufail A, Narendran N, Patel PJ, et al. Ranibizumab in myopic choroidal neovascularization: the 12-month results from the REPAIR study. Ophthalmology. 2013;120(9):1944-1945. e1941.

178. Wu PC, Chen YJ, Chen YH, et al. Factors associated with foveoschisis and foveal detachment without macular hole in high myopia. Eye. 2009;23(2):356-61.

179. Baba T, Ohno-Matsui K, Futagami S, et al. Prevalence and characteristics of foveal retinal detachment without macular hole in high myopia. Am J Ophthalmol. 2003;135(3):338-42.

180. Fang X, Weng Y, Xu S, et al. Optical coherence tomographic characteristics and surgical outcome of eyes with myopic foveoschisis. Eye. 2009;23(6):1336-42.

181. VanderBeek BL, Johnson MW. The diversity of traction mechanisms in myopic traction maculopathy. Am J Ophthalmol. 2012;153(1):93-102.

182. Yeh SI, Chang WC, Chen LJ. Vitrectomy without internal limiting membrane peeling for macular retinoschisis and foveal detachment in highly myopic eyes. Acta Ophthalmol. 2008;86(2):219-24.

183. Smiddy WE, Kim SS, Lujan BJ, Gregori G. Myopic traction maculopathy: spectral domain optical coherence tomographic imaging and a hypothesized mechanism. Ophthalmic Surg Lasers Imaging. 2009;40(2):169-73.

184. Gaucher D, Haouchine B, Tadayoni R, et al. Long-term follow-up of high myopic foveoschisis: natural course and surgical outcome. Am J Ophthalmol. 2007;143(3):455-62.

185. Ikuno Y, Sayanagi K, Soga K, Oshima Y, Ohji M, Tano Y. Foveal anatomical status and surgical results in vitrectomy for myopic foveoschisis. Jpn J Ophthalmol. 2008;52(4):269-76.

186. Ikuno Y, Sayanagi K, Ohji M, et al. Vitrectomy and internal limiting membrane peeling for myopic foveoschisis. Am J Ophthalmol. 2004;137(4):719-24.

187. Kuhn F. Internal limiting membrane removal for macular detachment in highly myopic eyes. Am J Ophthalmol. 2003;135(4):547-9.

188. Panozzo G, Mercanti A. Vitrectomy for myopic traction maculopathy. Arch Ophthalmol. 2007;125(6):767-72.

189. Kumagai K, Furukawa M, Ogino N, Larson E. Factors correlated with postoperative visual acuity after vitrectomy and internal limiting membrane peeling for myopic foveoschisis. Retina. 2010;30(6):874-80.

190. Kwok AK, Lai TY, Yip WW. Vitrectomy and gas tamponade without internal limiting membrane peeling for myopic foveoschisis. Br J Ophthalmol. 2005;89(9):1180-3.

191. Tang J, Rivers MB, Moshfeghi AA, Flynn HW, Chan CC. Pathology of macular foveoschisis associated with degenerative myopia. J Ophthalmol. 2010;2010:175613.

192. Sayanagi K, Morimoto Y, Ikuno Y, Tano Y. Spectral-domain optical coherence tomographic findings in myopic foveoschisis. Retina. 2010;30(4):623-8.

193. Spaide RF, Fisher Y. Removal of adherent cortical vitreous plaques without removing the internal limiting membrane in the repair of macular detachments in highly myopic eyes. Retina. 2005;25(3):290-5.

194. Ikuno Y, Gomi F, Tano Y. Potent retinal arteriolar traction as a possible cause of myopic foveoschisis. Am J Ophthalmol. 2005;139(3):462-7.

195. Sayanagi K, Ikuno Y, Gomi F, Tano Y. Retinal vascular microfolds in highly myopic eyes. Am J Ophthalmol. 2005;139(4):658-63. 
196. Benhamou N, Massin P, Haouchine B, Erginay A, Gaudric A. Macular retinoschisis in highly myopic eyes. Am J Ophthalmol. 2002;133(6):794-800.

197. Ripandelli G, Rossi T, Scarinci F, Scassa C, Parisi V, Stirpe M. Macular vitreoretinal interface abnormalities in highly myopic eyes with posterior staphyloma: 5-year follow-up. Retina. 2012;32(8):1531-8.

198. Michalewska Z, Michalewski J, Adelman RA, Nawrocki J. Inverted internal limiting membrane flap technique for large macular holes. Ophthalmology. 2010;117(10):2018-25.

199. Morizane Y, Shiraga F, Kimura S, et al. Autologous transplantation of the internal limiting membrane for refractory macular holes. Am J Ophthalmol. 2014;157(4):861-869 e861.

200. Leisser C, Hirnschall N, Doller B, et al. Internal limiting membrane flap transposition for surgical repair of macular holes in primary surgery and in persistent macular holes. Eur J Ophthalmol. 2018;28(2):225-8.

201. Ghosh B, Arora S, Goel N, et al. Comparative evaluation of sequential intraoperative use of whole blood followed by brilliant blue versus conventional brilliant blue staining of internal limiting membrane in macular hole surgery. Retina. 2016;36(8):1463-8.

202. Chen SN, Yang CM. Lens capsular flap transplantation in the management of refractory macular hole from multiple etiologies. Retina. 2016;36(1):163-70.

203. Alkabes M, Mateo C. Macular buckle technique in myopic traction maculopathy: a 16-year review of the literature and a comparison with vitreous surgery. Graefes Arch Clin Exp Ophthalmol. 2018;256(5):863-77.

204. Grewal DS, Mahmoud TH. Autologous neurosensory retinal free flap for closure of refractory myopic macular holes. JAMA Ophthalmol. 2016;134(2):229-30.

205. Chung K, Mohidin N, O'Leary DJ. Undercorrection of myopia enhances rather than inhibits myopia progression. Vis Res. 2002;42(22):2555-9.

206. Adler D, Millodot M. The possible effect of undercorrection on myopic progression in children. Clin Exp Optom. 2006;89(5):315-21.

207. Sun YY, Li SM, Li SY, et al. Effect of uncorrection versus full correction on myopia progression in 12-year-old children. Graefes Arch Clin Exp Ophthalmol. 2017;255(1):189-95.

208. Edwards MH, Li RW, Lam CS, Lew JK, Yu BS. The Hong Kong progressive lens myopia control study: study design and main findings. Invest Ophthalmol Vis Sci. 2002;43(9):2852-8.

209. Yang Z, Lan W, Ge J, et al. The effectiveness of progressive addition lenses on the progression of myopia in Chinese children. Ophthalmic Physiol Opt. 2009;29(1):41-8.

210. Correction of Myopia Evaluation Trial 2 Study Group for the Pediatric Eye Disease Investigator Group. Progressive-addition lenses versus single-vision lenses for slowing progression of myopia in children with high accommodative lag and near esophoria. Invest Ophthalmol Vis Sci. 2011;52(5):2749-57.

211. Berntsen DA, Sinnott LT, Mutti DO, Zadnik K. A randomized trial using progressive addition lenses to evaluate theories of myopia progression in children with a high lag of accommodation. Invest Ophthalmol Vis Sci. 2012;53(2):640-9.

212. Hasebe S, Jun J, Varnas SR. Myopia control with positively aspherized progressive addition lenses: a 2-year, multicenter, randomized, controlled trial. Invest Ophthalmol Vis Sci. 2014;55(11):7177-88.

213. Walline JJ, Lindsley K, Vedula SS, Cotter SA, Mutti DO, Twelker JD. Interventions to slow progression of myopia in children. Cochrane Database Syst Rev. 2011;12:CD004916.

214. Hasebe S, Ohtsuki H, Nonaka T, et al. Effect of progressive addition lenses on myopia progression in Japanese children: a prospective, randomized, double-masked, crossover trial. Invest Ophthalmol Vis Sci. 2008;49(7):2781-9.

215. Cheng D, Woo GC, Drobe B, Schmid KL. Effect of bifocal and prismatic bifocal spectacles on myopia progression in children: three-year results of a randomized clinical trial. JAMA Ophthalmol. 2014;132(3):258-64.

216. Lam CSY, Lee PK, Lam CSY, Tang WC, Lee PK, et al. Myopic control with multi-segment of myopic defocus (MSMD) spectacle lens: a randomized clinical trial. Birmingham, UK. 2017.

217. Sankaridurg P, Donovan L, Varnas S, et al. Spectacle lenses designed to reduce progression of myopia: 12-month results. Optom Vis Sci. 2010;87(9):631-41. 
218. Kanda H, Oshika T, Hiraoka T, et al. Effect of spectacle lenses designed to reduce relative peripheral hyperopia on myopia progression in Japanese children: a 2-year multicenter randomized controlled trial. Jpn J Ophthalmol. 2018;62(5):537-43.

219. Walline JJ, Jones LA, Mutti DO, Zadnik K. A randomized trial of the effects of rigid contact lenses on myopia progression. Arch Ophthalmol. 2004;122(12):1760-6.

220. Katz J, Schein OD, Levy B, et al. A randomized trial of rigid gas permeable contact lenses to reduce progression of children's myopia. Am J Ophthalmol. 2003;136(1):82-90.

221. Cho P, Cheung SW, Edwards M. The longitudinal orthokeratology research in children (LORIC) in Hong Kong: a pilot study on refractive changes and myopic control. Curr Eye Res. 2005;30(1):71-80.

222. Kakita T, Hiraoka T, Oshika T. Influence of overnight orthokeratology on axial elongation in childhood myopia. Invest Ophthalmol Vis Sci. 2011;52(5):2170-4.

223. Cho P, Cheung SW. Retardation of myopia in Orthokeratology (ROMIO) study: a 2-year randomized clinical trial. Invest Ophthalmol Vis Sci. 2012;53(11):7077-85.

224. Hiraoka T, Kakita T, Okamoto F, Takahashi H, Oshika T. Long-term effect of overnight orthokeratology on axial length elongation in childhood myopia: a 5-year follow-up study. Invest Ophthalmol Vis Sci. 2012;53(7):3913-9.

225. Charm J, Cho P. High myopia-partial reduction ortho-k: a 2-year randomized study. Optom Vis Sci. 2013;90(6):530-9.

226. Wen D, Huang J, Chen H, et al. Efficacy and acceptability of orthokeratology for slowing myopic progression in children: a systematic review and meta-analysis. J Ophthalmol. 2015;2015:360806.

227. Sun Y, Xu F, Zhang T, et al. Orthokeratology to control myopia progression: a meta-analysis. PLoS One. 2015;10(4):e0124535.

228. Lee YC, Wang JH, Chiu CJ. Effect of orthokeratology on myopia progression: twelve-year results of a retrospective cohort study. BMC Ophthalmol. 2017;17(1):243.

229. Yen MY, Liu JH, Kao SC, Shiao CH. Comparison of the effect of atropine and cyclopentolate on myopia. Ann Ophthalmol. 1989;21(5):180-182, 187.

230. Kinoshita N, Konno Y, Hamada N, Kanda Y, Shimmura-Tomita M, Kakehashi A. Additive effects of orthokeratology and atropine $0.01 \%$ ophthalmic solution in slowing axial elongation in children with myopia: first year results. Jpn J Ophthalmol. 2018;62(5):544-53.

231. Young AL, Leung AT, Cheng LL, Law RW, Wong AK, Lam DS. Orthokeratology lens-related corneal ulcers in children: a case series. Ophthalmology. 2004;111(3):590-5.

232. Rah MJ, Walline JJ, Jones-Jordan LA, et al. Vision specific quality of life of pediatric contact lens wearers. Optom Vis Sci. 2010;87(8):560-6.

233. Walline JJ, Gaume A, Jones LA, et al. Benefits of contact lens wear for children and teens. Eye Contact Lens. 2007;33(6 Pt 1):317-21.

234. Benavente-Perez A, Nour A, Troilo D. Axial eye growth and refractive error development can be modified by exposing the peripheral retina to relative myopic or hyperopic defocus. Invest Ophthalmol Vis Sci. 2014;55(10):6765-73.

235. Li SM, Kang MT, Wu SS, et al. Studies using concentric ring bifocal and peripheral add multifocal contact lenses to slow myopia progression in school-aged children: a meta-analysis. Ophthalmic Physiol Opt. 2017;37(1):51-9.

236. Shih YF, Chen CH, Chou AC, Ho TC, Lin LL, Hung PT. Effects of different concentrations of atropine on controlling myopia in myopic children. J Ocul Pharmacol Ther. 1999;15(1): $85-90$.

237. Chua WH, Balakrishnan V, Chan YH, et al. Atropine for the treatment of childhood myopia. Ophthalmology. 2006;113(12):2285-91.

238. Chia A, Chua WH, Cheung YB, et al. Atropine for the treatment of childhood myopia: safety and efficacy of $0.5 \%, 0.1 \%$, and $0.01 \%$ doses (Atropine for the Treatment of Myopia 2). Ophthalmology. 2012;119(2):347-54.

239. Tong L, Huang XL, Koh AL, Zhang X, Tan DT, Chua WH. Atropine for the treatment of childhood myopia: effect on myopia progression after cessation of atropine. Ophthalmology. 2009;116(3):572-9. 
240. Chia A, Chua WH, Wen L, Fong A, Goon YY, Tan D. Atropine for the treatment of childhood myopia: changes after stopping atropine $0.01 \%, 0.1 \%$ and $0.5 \%$. Am J Ophthalmol. 2014;157(2):451-457 e451.

241. Ashby R, Ohlendorf A, Schaeffel F. The effect of ambient illuminance on the development of deprivation myopia in chicks. Invest Ophthalmol Vis Sci. 2009;50(11):5348-54.

242. Seidemann A, Schaeffel F. Effects of longitudinal chromatic aberration on accommodation and emmetropization. Vis Res. 2002;42(21):2409-17.

243. Flitcroft DI. The complex interactions of retinal, optical and environmental factors in myopia aetiology. Prog Retin Eye Res. 2012;31(6):622-60.

244. Hung LF, Arumugam B, She Z, Ostrin L, Smith EL. Narrow-band, long-wavelength lighting promotes hyperopia and retards vision-induced myopia in infant rhesus monkeys. Exp Eye Res. 2018;176:147-60.

Open Access This chapter is licensed under the terms of the Creative Commons Attribution 4.0 International License (http://creativecommons.org/licenses/by/4.0/), which permits use, sharing, adaptation, distribution and reproduction in any medium or format, as long as you give appropriate credit to the original author(s) and the source, provide a link to the Creative Commons license and indicate if changes were made.

The images or other third party material in this chapter are included in the chapter's Creative Commons license, unless indicated otherwise in a credit line to the material. If material is not included in the chapter's Creative Commons license and your intended use is not permitted by statutory regulation or exceeds the permitted use, you will need to obtain permission directly from the copyright holder.

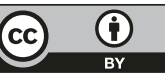

